\title{
Technology-Enabled Learning and Post-Pandemic Academic Scene in India: Some Reflections
}

Dr Merry Baruah Bora ${ }^{\dagger}$

\section{Abstract}

The onslaught of the Covid pandemic has changed the landscape of human interactions and life drastically; after the apparent changes in the health sector, the field of education has been radically changed. This study makes an effort to deliberate upon some aspects of the National Education Policy, 2020(NEP) and Right to Education (RTE) in relation to the post-pandemic changes that have been seen in the present Indian educational scene, especially in the context of the technology-enabled learning.

Keywords: National Education Policy (NEP); Right to Education (RTE); Technology Enabled Learning; Democracy; Pandemic

\footnotetext{
${ }^{\dagger}$ Associate Professor, Department of English, Cotton University, Emails: merry.baruah@cottonuniversity.ac.in; merrybaruah@rocketmail.com

(C) 2021 Baruah Bora. This is an Open Access article distributed under the terms of the Creative Commons Attribution License (http://creativecommons.org/licenses/by/2.0), which permits unrestricted use, distribution, and reproduction in any medium, provided the original work is properly cited.
} 


\section{Introduction}

When Covid 19 pandemic took the world unaware and fear psychosis shocked the world out of its complacent living some two years ago, the lived lives of people across the globe - the health ecosystem received a significant jolt, and millions of people succumbed to the deadly virus. Undoubtedly, the health sector was most acutely affected and the system collapsed in most places across the world. Now when the lives are limping back to the semblance of normalcy and people have acquired certain skills of coexisting with the deadly virus, patterns of changes that had come upon life consequent to the pandemic has become discernible. Drastically changing the health scene, the pandemic seems to have left no corner of life unaffected - individual and social lives in the sphere of education, economy, religion, culture, politics have undergone changes of the extreme kind. For a country of the stature of India, the pandemic in itself was overwhelming enough to leave an indelible mark on the collective unconscious of the people besides bringing about ubiquitous transformation. With very little preparation for disaster control or damage minimisation infrastructure that includes health care facilities especially added to the enormous population, the pandemic was and is still an awful experience for India. This special issue of the journal Space and Culture, India is a homage paid to the renowned Indian geographer, the great educationist, late Professor Ram Babu Singh, who retired from the Department of Geography, Delhi School of Economics, New Delhi.

This Editorial begins with a brief description of the ongoing issues kindled by the COVID-19 pandemic. Following this, I discuss the development of a more equitable foundation of society.

\section{Issues Engendered by the Pandemic}

The pandemic undoubtedly is a health emergency, and lives need to be saved and protected against its fatal onslaught. However, it is essential to remember that there are other layers to life- namely, education, economics, and emotional well-being, which suffered tremendous setbacks, causing almost irreparable damages due to the Covid-19 pandemic. The article shall not address the politics of the pandemic, the issues related to the conspiracy theory that flooded the social media especially - for discourse of any nature is imbued with the politics of construction, and its 'truth' quotient remains under suspicion. Nonetheless, there are issues that defy 'politicalness' - the human question in these issues is too overwhelming to be narrowed down to the politics of discursive practices. As the primary concern of this piece of writing is education, especially in the post-pandemic context in India, I shall make an attempt to analyse how education has received a significant jolt worsening the scene further in the country while creating potential scope for violation of the human right and intensifying social inequality.

And additionally, the private/corporate schools and educational institutions shall be excluded from the purview of the present study. In this context, it would do good to keep in mind that the United Nations' International Covenant on Economic, Social and Cultural Rights recognises the Right to Education as a human right that envisages free and compulsory education for all, among others. The National Education Policy (NEP), which came into force in India quite contemporaneously, shall be considered a point of reference in relation to its thrust on the digitisation and technology-enhanced imparting of education. Education is besides a fundamental right as per the provision of the Indian Constitution (86 ${ }^{\text {th }}$ Amendment Act, 2002, Article 21-A). A glance at the provisions under Right to Education (RTE) and National Education Policy (NEP), 2020 taken together reveals that education should be free and compulsory for children from age group six to eighteen. If one looks at education as an ongoing, continuous process, it may well extend beyond the age specified in the constitutional provisions. The stages of education that fall into the age group mentioned - Foundational, Pre School, 
Preparatory, Middle and Secondary stages as indicated in the mentioned documents (RTE, NEP). The systemic structure of education that had been in place in India appears well demarcated into these stages, and schools, colleges and universities more or less had been working towards fulfilment of the goals designed specifically for each of these stages. Since the last decade or so, the government, both at the centre and the states, has been investing significantly to develop infrastructure and rise in gross enrolment ratio through particular phase wise implementation of steps under the RTE.

The ubiquitous presence of the Covid pandemic in people's lives post-2019 has brought about drastic changes that are here now to stay for some time. Lives are deranged in all aspectseducation being one crucial aspect among all. The education system of any given country is the foundation of its future as it is in this sphere that the vital task of shaping the future of a country is accomplished; children and youth of a country are the most potent assets and their transformation into productive human resources is achieved, significantly through education. With the ravaging intrusion of the pandemic, the conventional practices of classroom teaching-learning exercises were disrupted, suspended for months together, and the students at the preparatory and middle school stages have been away from school for several months now. Academic activities at high school and higher education were resumed for a few months, and once again, with the rise in the fatalities, these were suspended. The physical and spatial interaction of the learners with the environment had come to a standstill. However, there are issues related to academic year loss that governments had to decide upon, and virtual became an option not only for the conduct of regular classes but also evaluation and assessment adopted for all stages of learners in India. Notwithstanding the air of emergency owing to the pandemic that permeated the sphere of academics and formal education, one needs to realise that despite all well-meaning efforts in introducing the virtual classrooms and acknowledging the digital mode as one of the most potential tools for education in a country like India, the larger picture offers little respite!

Education does not happen exclusive of the existential realities and milieu - the larger social, political and economic contexts influence the individual's lived life in all its aspects. With formal education going virtual and the digital becoming the dominant platform for academic exercises, there seems to be a widening divide between the students along the lines of the economic, spatial and gender perspectives new margins are now thus created. One must remember that India is still struggling with its divisive forces within the discourse of caste, religion, and economic spheres. Even before Covid, the education sector presented a dismal scene in general, as one moved into its rural heartland where class/caste considerations made learning a challenge. In the postpandemic context, the already existing marginalities have intensified; with deteriorating economic situation and heads of the families left jobless, schools closed for the pandemic, children of the rural and urban poor families are suffering nutritional issues as they are deprived of their free meals under the Mid-day Meal Scheme - against such a backdrop a large crosssection of Indian society belonging to the rural and urban poor families shall certainly have an extremely challenging time to continue with education which has undergone radical transformation with the all pervading presence of technology that has now become an aspect of the 'new normal'.

Democratic foundations of society rest upon its opening up of various spaces allowing healthy interactions among all stakeholders. In the case of the work from home and by extension, the 'learn from home' culture that has been introduced in the country consequent to the pandemic, the spaces appear 'closed and confined'. This closure and confinement may be understood in terms of quantifiable parameters and a more abstract level of development of thought and ideas, emotional well-being, and overall health of the individual learners. The classrooms were a broad landscape that allowed a healthy intermingling of a varied group of 
learners, which in the virtual situation is not possible - for learning to be fruitful, certain spatial requirements need to be fulfilled. Imagine, for instance, a middle school-going teenager from an urban poor family trying to attend classes from home - access to the stable physical environment, technology and emotional well-being required for adequate learning stand compromised. In this context, it would be pertinent to refer to an article by Amar Chanchal (2014) from the Centre for Budget and Governance Accountability, New Delhi. Discussing the issue, he stated,

The report of the 'Expert Group to review the methodology for measurement of Poverty' headed by C. Rangarajan has put the number of urban poor at 102.5 million in 2011-12, surviving on daily consumption expenditure of [INR] 47 or less. However, it is argued by many that instead of measuring urban poverty just in terms of consumption expenditure, it needs to be defined in terms of access/non-access to basic amenities. (page1, emphasis mine)

These statistics perhaps would suffice to enlighten one upon the urban poor's issues - the layers of vulnerabilities they experience while living in the urban spaces primarily designated as slums. It is also important to remember that the figures were indicative of the situation a decade ago; in the same piece of writing, it was assumed that "[t]he pace of urbanisation is likely to accelerate over time and it is estimated that by 2030, another 250 million people would be added to the Indian cities." Going by this, India's urban poor might have risen up by now and is moving towards the figures indicated above. What will then be the implications of this data in the education scene in the aftermath of the pandemic in India? Let us also not forget that the RTE is a fundamental right in India- with physical schools becoming almost redundant for certain age groups, how are the digital/virtual platforms going to compensate for the loss of learning in this socially and economically vulnerable section of the population? In addition to this, when one considers the caste and gender implications within the urban poor, the divide becomes discernible all the more. For example, the housing condition in the slums do not adhere to the safe and secure environment norm where teaching learning shall be subjected to various constraints and virtual classes may not at all be practically possible due to the absence of resources that include finances and technologynetwork and smartphone or a computer at the most would be probably a heavy burden for these families. Even if a few may possess these, the spatial situation plays a crucial role in affecting the qualitative aspect of the entire teaching-learning process. The highly dense spaces of the slums do not provide the minimum required atmosphere for education, and children in such situations shall be compelled to give up the efforts to learn gradually, and this phenomenon shall be more visible when one comes to gender, caste considerations. The National Consultation on Safe and Secure Education, held in 2019 under the aegis of Right to Education Forum, released a policy brief titled 'Gendered Impact of Covid-19 on the education of school-aged children in India', which presents a rather dismal picture. Apart from many findings that do cause worry, a cursory glance at the following would suffice to comprehend the gravity of the marginalisation that has been gradually afflicting the lives of the underprivileged to the extent of deprivation and exclusion:

The socio-economic profiles of families who were a part of the study, were tilted towards more marginalised groups: $36 \%$ OBCs, $39 \% \mathrm{SC} / \mathrm{STs}$ and $18 \%$ minorities. The adolescent girls and boys interviewed were in upper primary/early secondary (grades 6-8) [49\%] and secondary (grades 9-10) [23\%] grades. Therefore, most children were in formative years of learning and at critical phases of transition marked by the movement from upper-primary to secondary, or from secondary to senior secondary stages. The literature shows that most students drop out at transitional stages, between class 5 and 6 for elementary, 10 and 11 for secondary 
and between class 12 and higher education for tertiary (Ghatak et al., page 2).

The above information represents the aggregate overall picture of marginalised communities; when one adds the gender, religion and caste/tribe parameters into this data, there is a further marginalisation- without the school/college campus now entering into the space of 'home' through the technology-enabled infrastructure, girls were confined to the genderspecific roles assigned to them. Education of the girl child/girls was relegated to the secondary sphere as they had to give their time in various domestic chores which included cooking, cleaning and taking care of younger siblings, whereas the male counterparts in a similar situation had the freedom to use their time in learning if the prevailing circumstances allowed.

\section{Conclusion: Towards a More Equitable Foundation of Society}

The discriminatory practices embedded within the socio-cultural ethos of India deepened and intensified with the pandemic - caste, class, gender, religion, among others, are the dominant factors that enhanced the marginalisation. Moving into the rural landscape, these issues become starker. The absence of a smooth communication network, prevalent discriminatory socio-cultural practices, poor financial status, among others, create challenges for the efficacy of the RTE guaranteed to every child by our Constitution. While the pandemic has made technology enabled learning an inevitable option for teaching learning to continue uninterrupted, the vast majority of underprivileged children in India both in urban spaces and elsewhere, are still struggling to keep pace with the new discourse of development; the 'new normal' has added unprecedented obstacles to the already existing chasm present in the country's socio-cultural, political fabric making way for the deepening of the problem. One needs to display a compassionate and empathetic assessment of the situation that would pave the way for inclusive growth in all senses of the term. Education is one of the essential criteria in development and empowerment discourse; let us not forget the element of sustainability that underlies these parameters in the absence of which fundamental rights of the country's majority citizens stand compromised. There is an impending risk of Constitutional violation if adequate and realistic measures are not adopted for the mitigation and assuaging of the challenges outlined above- technologyenabled learning and the extensive use of the virtual platform for teaching shall otherwise be the exclusive domain for an elite class of Indians leading to the intensification of deprivation and disempowerment that may soon weaken the very foundations of democracy in India.

\section{References}

Chanchal, Amar (2014). Urban Poor in India:

Addressing the Challenges.

https://www.cbgaindia.org/wp-

content/uploads/2014/01/Urban-poor-in-India-

Addressing-the-challenges.

Ghatak,Neha, Yareseeme, Achala S and Jha Jyotsna (2020). Gendered Impact of Covid-19 on education of school-aged children in India. http://rteforumindia.org/wpcontent/uploads/2021/03/National-PolicyBrief.pdf

International Covenant on Economic, Social and Cultural Rights. United Nations, 1966. https://www.equalityhumanrights.com

National Education Policy, 2020 - Ministry of Education.https://www.education.gov.in/sites/ upload_files/mhrd/files/NEP_Final_English_0.p $\mathrm{df}$

The Right of Children to Free and Compulsory Education Act, 2009. https://legislative.gov.in/ 